\title{
Design of Compact Monopole Antenna using Double U-DMS Resonators for WLAN, LTE, and WiMAX Applications
}

\author{
Ahmed Boutejdar ${ }^{* 1}$, Mohammad Ahmad Salamin ${ }^{2}$, Saad Dosse Bennani ${ }^{3}$, Soumia El Hani ${ }^{4}$ \\ ${ }^{1}$ Germany research Foundation (DFG), Bonn-Braunschweig, Germany \\ ${ }^{2}$ Electrical, Communication and Electronics Engineering, Palestine \\ ${ }^{3}$ Laboratoire des Energies Renouvelables et Systèmes Intelligents (LERSI) - FSTF, \\ Ecole Nationale des Sciences Appliquées-Fès (ENSAF), Université Sidi Mohamed ben Abdellah, \\ Fès, Morocco \\ ${ }^{4}$ Higher National School of mines, Rabat, Morocco, Mohammed V University in Rabat, ENSET, Morocco \\ *Corresponding author, e-mail: boutejdar69@gmail.com
}

\begin{abstract}
In this research, a novel wide-band microstrip antenna for wideband applications is proposed. The proposed antenna consists of a square radiating patch and a partial ground plane with a smal rectangular notch-shape. Two symmetrical $U$-slots are etched in radiating patch. The defected microstrip $U$-shapes and the small notch improve the antenna characterestics such impedance wideband and the gain along the transmission area. The proposed antenna is simulated on an FR4 substrate of a dielectric constant of 4.3, thickness $1.6 \mathrm{~mm}$, permittivity 4.4, and loss tangent 0.018 . The simulation and optimization results are carried out using CST software. The antenna topology occupies an area of $30 \times 40 \times 0.8 \mathrm{~mm}^{3}$ or about $0.629 \lambda_{g} \times 0.839 \lambda_{g} \times 0.017 \lambda_{g}$ at $3 \mathrm{GHz}$ (the centerresonance frequency). The antenna covers the range of 2.1711 to $4.0531 \mathrm{GHz}$, which meet the requirements of the wireless local area network (WLAN), worldwide interoperability for microwave access (WiMAX) and LTE (Long Term Evolution) band applications. Good VSWR, return loss and radiation pattern characteristics are obtained in the frequency band of interest. The obtained Simulation results for this antenna depict that it exhibits good radiation behavior within the transmission frequency range.
\end{abstract}

Keywords: Microstrip Antenna, Wide-band, WiMAX, WLAN, LTE

Copyright ( 2017 Universitas Ahmad Dahlan. All rights reserved.

\section{Introduction}

Current revolution in Telecommunication and Electronic filed has a lot of challenges including design and development of a small size, high efficiency, and low cost antenna for used in large field in telecommunication such as wireless local area network (WLAN), world wide inter-operability for microwave access (WiMAX), satellite communication, and space craft [1]. Having variety of beneficial properties i.e. mechanical durability, conformability, low cross polarized radiation patterns and economical fabrication; microstrip patch antennas became renowned in wireless communication systems [2]. The development of antenna for wireless communication system also requires an antenna with multi operating frequency, this is mainly due to the various wireless communication system operate using various frequency and hence the multi band antenna can be used in the same time for different application at the same time [3]. LTE (Long Term Evolution) is the project related to high performance air interface for mobile telephony. LTE is the latest new technology that ensures competitive edge over existing standards: GSM, UMTS, etc. It improves user experience with full mobility. LTE minimizes the system and user-equipment complexities. Several designsof different antennashave been proposed and published for wireless communication system such as WLAN, LTE and WiMAX applications [4-20]. The most important drawback of microstrip antennas is narrow bandwidth. Maximum $8 \%$ bandwidth is available with classical microstrip antennas. To overcome this drawback, several methods have been devised by researchers [21-29]. Extensive research and development of microstrip patch antenna was done. In [30] a broadband stacked U-slot microstrip patch antenna is presented. The single $U$ slot is used based on circuit theory concept to provide dual-band broadband characteristics, the bandwidth enhancement by $33.52 \%$ by 
inserting U-slot in the patch. In [31] a Broadband high gain microstrip patch antenna using slot is proposed. Double U-slot in the patch is used and the dual band characteristic is obtained. The antenna has $37 \%$ impedance bandwidth. In [32] design of a broadband printed microstrip antenna for WLAN and WiMAX application is presented, which a two parasitic elements are printed in the ground plane, this provide a good performance of the antenna. In [31] a novel dual band antenna with two U-shaped slots is presented. By using two slots the dual band characteristics are obtained. The bandwidth of the antenna was enhancement by using tow Lshaped in the ground plane this antenna is suitable for WLAN and WiMAX applications.

This letter focuses on a square monopole antenna for bandwidth applications, which combines the square-patch approach with etched defected microstrip U- shape, and the partial ground plane with an inserted shape. The antenna condidat achieves a fractional bandwidth of more than $60.4 \%$. Also by using two DMS-U slots [32] and the back-ground notch, a bandwidth performance has been realised. The moification of the U-DMS-arms as well as of the dimensions of the notch allows a control of the wide of the bandwidth and of the gain factor.

The proposed antenna occupies a compact size of $30 \times 40 \times 0.8 \mathrm{~mm}^{3}$, and the impedance bandwidth of the designed antenna is higher than the UWB antennas reported recently [33-36].

Good $S_{11}$-s cattering, VSWR and radiation pattern features are obtained in the frequency band of interest. Simulated results are presented to validate the usefulness of the proposed antenna topology for wireless communication technologies

\section{Antenna Design}

The proposed antenna is designed using FR4 as substrate which has a relative permittivity of 4.3 . The dimensions of the antenna are $30 \times 40 \times 0.8 \mathrm{~mm}^{3}$. The patch is easily fed using a $50 \Omega$ microstrip feed line. A rectangular radiation patch with a $U$-shaped slot is used on the top face of the substrate. In order to enhance bandwidth and to create extra bands more than in [34], the position, thickness, and length of the double U-shaped slots are properly adjusted. The partial ground plane is used to enhance the bandwidth of the proposed antenna. Figure 1 shows the dimensions of the proposed antenna, and Table 1 include the value of each dimension.

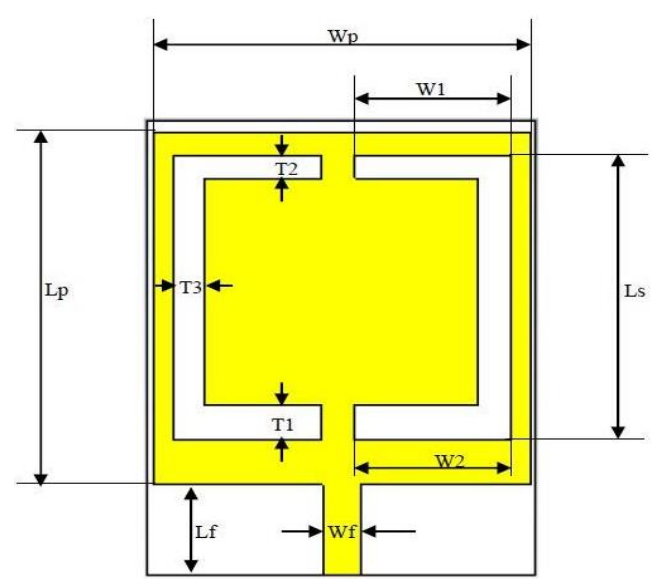

(a) Front view

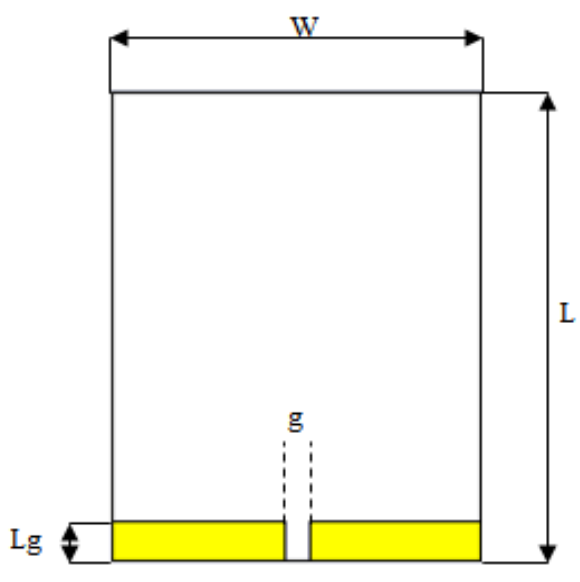

(b) Back view

Figure 1. Structure of the proposed antenna

Table I. Parameters of the proposed antenna in $(\mathrm{mm})$

\begin{tabular}{ccccccc}
\hline $\mathrm{L}$ & $\mathrm{W}$ & $\mathrm{Lg}$ & $\mathrm{g}$ & $\mathrm{Lp}$ & $\mathrm{Ls}$ & $\mathrm{Wp}$ \\
\hline 40 & 30 & 3.4 & 2 & 31 & 25 & 29 \\
W1 & W2 & Wf & Lf & T1 & T2 & T3 \\
12 & 12 & 2.9 & 8 & 3 & 2 & 2.3 \\
\hline
\end{tabular}




\section{Results and Analysis}

\subsection{Current Distribution}

In order to understand the behavior of the bands characteristics, the simulated current distribution of the proposed antenna at each resonant frequency are shown in Figure 2. The current distribution at $2.45 \mathrm{GHz}$ is shown in figure 2(a), at $2.6 \mathrm{GHz}$ is shown in Figure 2 (b), and at $3.69 \mathrm{GHz}$ is shown in Figure 2 (c).

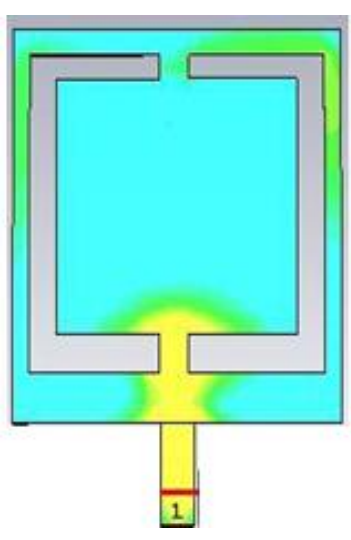

(a)

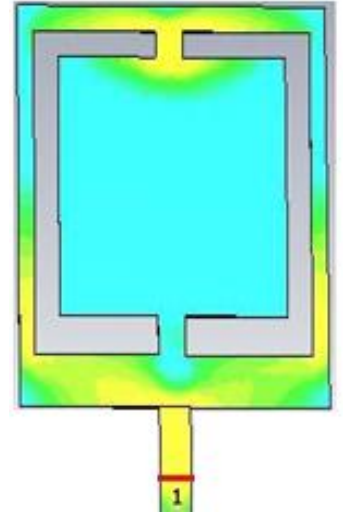

(b)
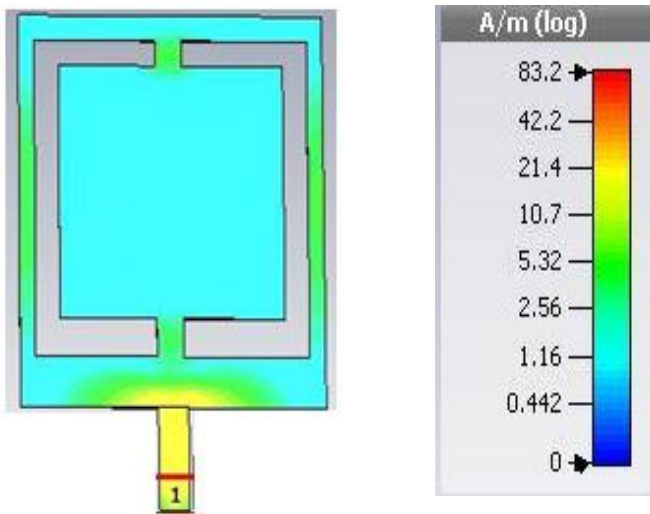

(c)

Figure 2. Current distribution of the proposed antenna (a) $2.45 \mathrm{GHz}$. (b) $2.60 \mathrm{GHz}$. (c) $3.69 \mathrm{GHz}$

Figure 2 (a) shows that the current is mainly concentrated at the gap between the two $U$ shaped slots above the feed line. At $2.60 \mathrm{GHz}$, Figure 2 (b) shows that the current is mainly concentrated at the gap between the two $U$ shaped slots at the upper side, and also around the lower $U$ shaped slots. At $3.69 \mathrm{GHz}$, figure 2 (c) shows that the current is concentrated at the upper and lower gaps between the two $U$ shapedslots.

\subsection{Parametric Analysis}

The important criteria in the design of the desiered Wide-abnd antenna are to control the center frequency of each band. In this parametric study, the the parameters with dominant effect on the performance of the antenna are invistgated. Figure 3 (a) shows the simulated return loss of the proposed antenna for different widths of $\mathrm{g}$, which represents the width of the gap. The width of the gap which is introduced in the ground plane affects each resonant frequency at 2.45, 2.60, and $3.69 \mathrm{GHz}$ which can increase or decrease the $\mathrm{S} 11$ magnitude in $\mathrm{dB}$. It also makes resonant frequency at $3.69 \mathrm{GHz}$ to be shifted, as shown in Figure 3 (a). Figure 3 (b) shows the simulated return loss of the proposed antenna for various W1. It can be seen that the length of $W 1$ affects the resonant frequency at $2.60 \mathrm{GHz}$, while there is a little effect at the resonant frequency at $2.4 \mathrm{GHz}$ which is agrees with the current distribution at figure 2(b). Figure 4 (a) shows the simulated return loss of the proposed antenna for various W2. It can be seen that the length of W2 affects the resonant frequency at $2.45 \mathrm{GHz}$, while there is a little effect at $2.60 \mathrm{GHz}$ which agrees with current distribution at Figure 2 (a). Slotted shape, as called quasi defected ground structure (QDGS) or ground notch can be realised by etching off a simple geometric form in the partial ground plane. The notch topology can take diffrentformes such half circle, quasi arrowhead or rectangulare. Analog to DMS and DGS, the slot (QDGS) in a ground plane excited by the microstrip line works as an evanescent mode waveguide section. Combined with the coupling capacitor between the microstrip and the slot, the DGS produces a band- reject resonance. The improvement of reject- as well as accept- band and thus the increasing of the impedance widthband, due to the QDGS placed in the partial ground plane can be explained by the effect of QDGS on the feld distribution [37, 38]. An etched defect disturbs the shield current distribution in the ground plane. This disturbance can change characteristics of a transmission line such as line capacitance and inductance. This gives rise to an increase the effective capacitance and inductance of a transmission line, respectively. The 
QDGS slot is modeled by a parallel LC resonant circuit. Briefly, based on investigated simulation, it can be shown that a ground slot incorporated under the $50 \mathrm{ohm}$ microstrip feed line can used to perturb an additional resonance at higher frequencies and increase the bandwidth without affecting much the performance of the antenna.

In order to enhance the performance of the antenna, a gap is introduced in the ground plane, as shown in Figure 1(b). The effect of this gap is studied on the return loss of the proposed antenna as shown in Figure 4 (b). As noticed from Figure 4 (b), the return loss of the proposed antenna is enhanced by using this gap in the ground plane of the antenna. Table 2 below shows a comparison between the return loss of the antenna before and after the use of this gap.
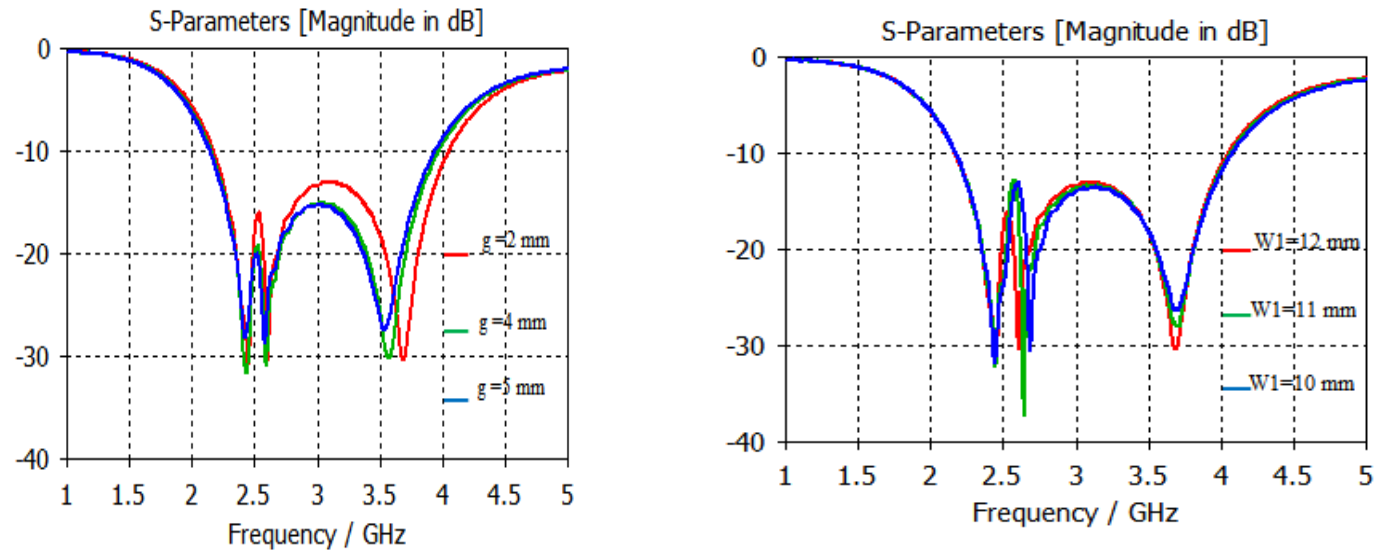

Figure 3. Simulated return loss of the proposed antenna, (a) for various values of $g$, (b) for various length of $\mathrm{W} 1$
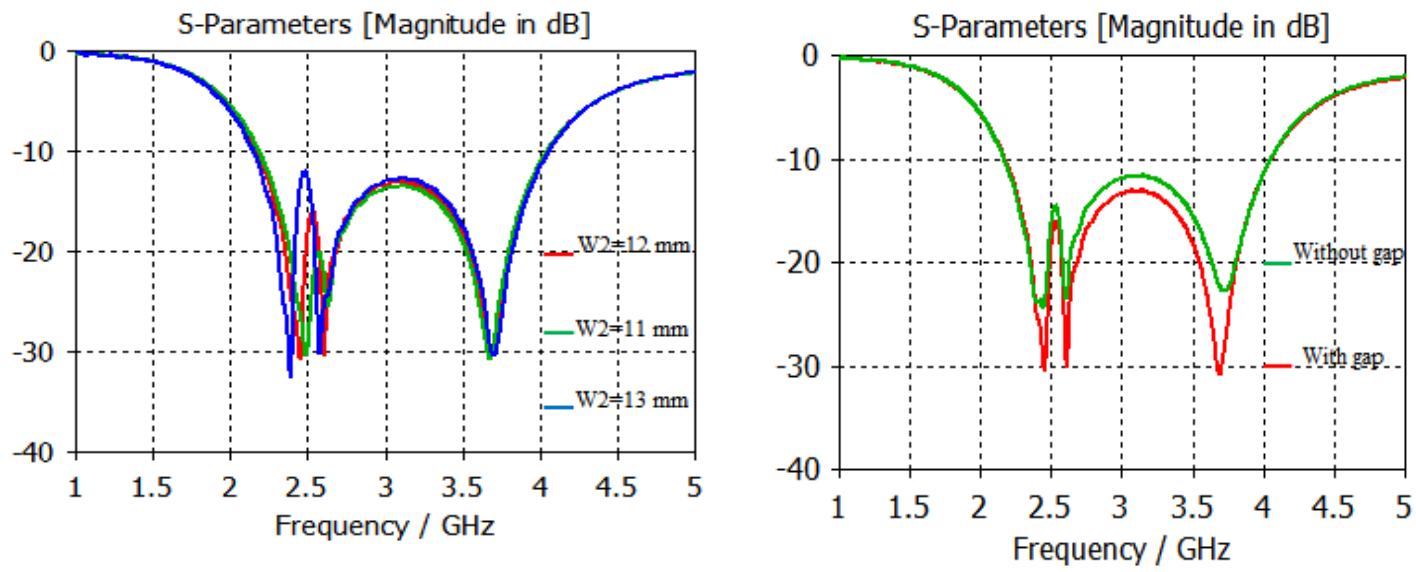

Figure 4. Simulated return loss of the proposed antenna, (a) for various length of W2, (b) with and without a gap

Table 2. Effect of the Gap at the Return Loss of the Proposed Antenna

\begin{tabular}{ccc}
\hline Resonant frequency $(\mathrm{GHz})$ & Withoutgap $\left(\mathrm{S}_{11} / \mathrm{dB}\right)$ & Withgap $\left(\mathrm{S}_{11} / \mathrm{dB}\right)$ \\
\hline $2.45 \mathrm{GHz}$ & -24.245 & -30.388 \\
$2.60 \mathrm{GHz}$ & -23.577 & -30.01 \\
$3.69 \mathrm{GHz}$ & -22.774 & -30.735 \\
\hline
\end{tabular}




\subsection{Results and Discussion}

The simulated results are done by using Computer Simulation Technology (CST). Figure 5 (a) shows the simulated $\mathrm{S}_{11}$ curve against frequency. The proposed antenna has triple operating frequencies with the central frequency of $2.45,2.60$, and $3.69 \mathrm{GHz}$.Figure 5 (a) also shows the bandwidth of the proposed antenna. The Fractional Bandwidth (FBW): is the ratio of the difference of the upper and lower frequencies of acceptable operation to the center frequency of the band multiplied by 100 . Figure 5 (b) shows the VSWR of the proposed antenna. VSWR is a measure of how well matched an antenna is to the cable impedance. A perfectly matched antenna would have a VSWR of 1:1. As noticed from Figure 5 (b) below, the VSWR of the proposed antenna is equal 1 at each operating frequency. This indicate that the proposed antenna have a good impedance matching.

BW of the antenna $=4.0531 \mathrm{GHz}-2.1711 \mathrm{GHz}=1.882 \mathrm{GHz}$.

FBW at $2.45 \mathrm{GHz}=\mathrm{BW} / 2.45=(1.882 / 2.45)^{*} 100 \%=76.81 \%$.

FBW at $2.60 \mathrm{GHz}=\mathrm{BW} / 2.60=(1.882 / 2.60) * 100 \%=72.38 \%$.

FBW at $3.69 \mathrm{GHz}=\mathrm{BW} / 3.53=(1.882 / 3.69) * 100 \%=51.00 \%$.

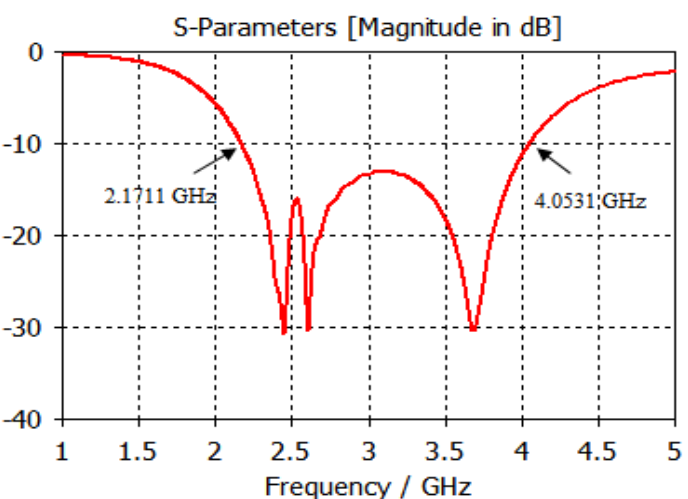

(a)

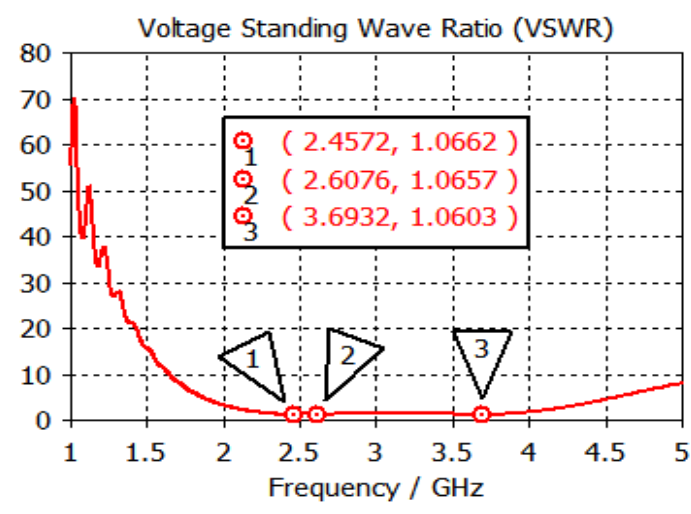

(b)

Figure 5. Simulated results of the proposed antenna, (a) $S_{11}$ versus frequency, (b) VSWR

The radiation pattern of the proposed antenna is simulated using CST software. Figure 6 shows the radiation patterns of the proposed antenna in the E-plane and $\mathrm{H}$-plane at the frequencies of $2.45 \mathrm{GHz}, 2.60 \mathrm{GHz}$, and $3.69 \mathrm{GHZ}$ respectively. As shown in figure 6 , the antennahasa bi-directional radiation at $\mathrm{E}$-plane and $\mathrm{H}$-plane. The measured directivity of the proposed antenna at the frequencies $2.45 \mathrm{GHz}, 2.60 \mathrm{GHz}$, and $3.69 \mathrm{GHz}$ are $2.45 \mathrm{dBi}, 2.55 \mathrm{dBi}$, and $4.24 \mathrm{dBi}$ respectively. Hence, the proposed antenna can provide sufficient gain and stable radiation patterns, which make it suitable and preferred for various wireless communication systems.Table 3 introduces a comparison between the proposed antenna and other related works in terms of size, relative permittivity, bandwidth and operating frequency.

Table 3. Comparison Between Different Designs

\begin{tabular}{|c|c|c|c|c|c|c|}
\hline \multirow[b]{2}{*}{ Ref. } & \multirow{2}{*}{ Size $\left(\mathrm{mm}^{3}\right)$} & \multirow[b]{2}{*}{$\varepsilon_{\mathrm{r}}$} & \multirow{2}{*}{ Feed method } & \multicolumn{3}{|c|}{ Operating Frequency (GHz) } \\
\hline & & & & $1^{\text {st }}$ band & $2^{\text {nd }}$ band & $3^{\text {rd }}$ band \\
\hline [27] & $41.4 \times 51.9 \times 1.6$ & 4.2 & Microstrip line & $1.56(115 \%)$ & $\begin{array}{c}2.364 \\
(76.14 \%)\end{array}$ & $(60 \%)$ \\
\hline [32] & $40 \times 50 \times 1.6$ & 4.3 & Microstrip Line & $\begin{array}{c}2.4 \\
(73.67 \%)\end{array}$ & $\begin{array}{c}3.5 \\
(50.51 \%)\end{array}$ & $\longrightarrow$ \\
\hline [33] & $34.5 \times 40 \times 0.8$ & 2.95 & CPW & $\begin{array}{c}2.45 \\
(65.4 \%)\end{array}$ & $\begin{array}{c}3.44 \\
(45.6 \%)\end{array}$ & - \\
\hline $\begin{array}{l}\text { This } \\
\text { work }\end{array}$ & $30 \times 40 \times 0.8$ & 4.3 & Microstrip line & $\begin{array}{c}2.45 \\
(76.81 \%) \\
\end{array}$ & $\begin{array}{c}2.60 \\
(72.38 \%) \\
\end{array}$ & $\begin{array}{c}3.69 \\
(51.00 \%) \\
\end{array}$ \\
\hline
\end{tabular}


E-plane

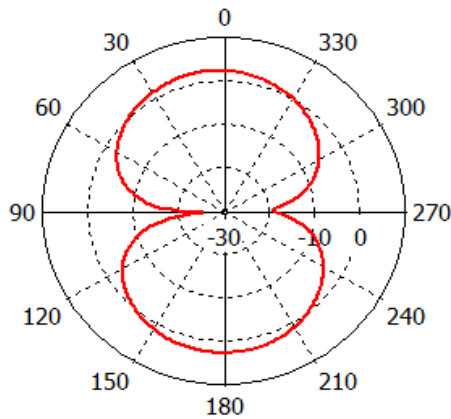

E-plane

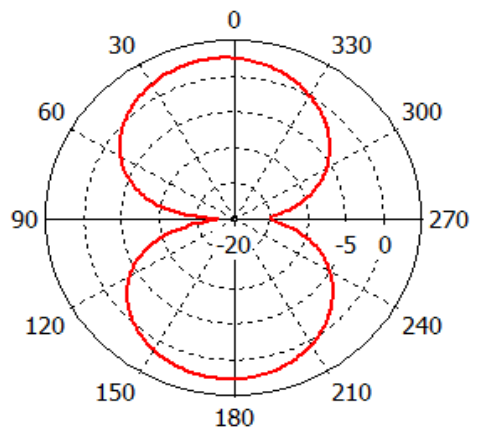

E-plane

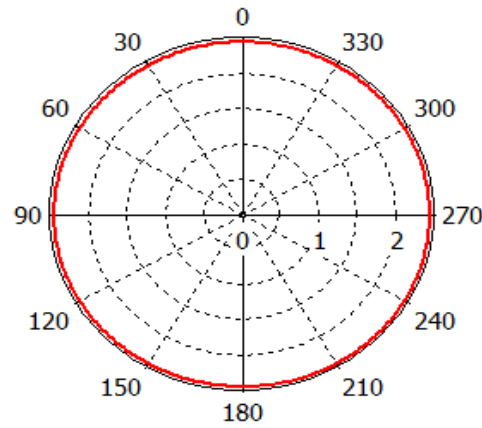

H-plane

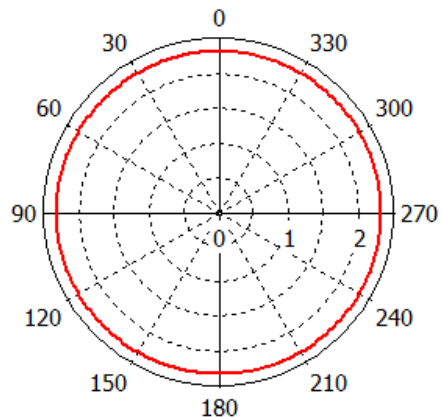

(a)

H-plane

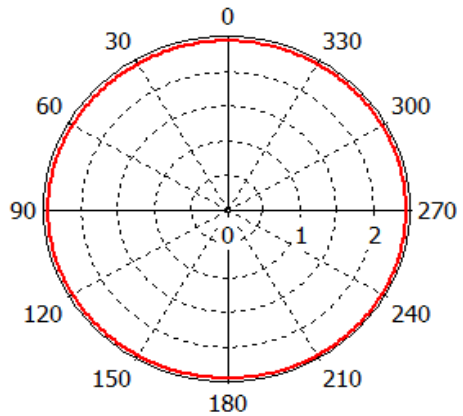

(b)

H-plane

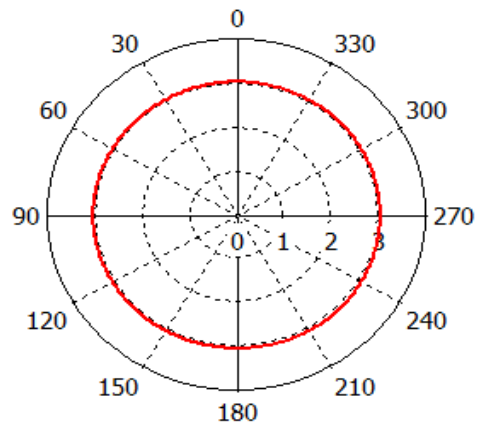

(c)

Figure 6. Normalized 2-D radiation patterns of the proposed antenna.

(a) $2.45 \mathrm{GHz}$, (b) $2.60 \mathrm{GHz}$, (c) $3.69 \mathrm{GHz}$

\section{Conclusion}

A novel compact monopole antenna with wide bandwidth features is presented in this work. The operating frequency range of the proposed topology satisfies the 10-dB return loss requirement from 2.1711 to $4.0531 \mathrm{GHz}$. In order to improve the impedance bandwidth and radiation characteristics of the investigated antenna, $U$ defected microstrip shapes and a small notch are etched on radiating patch and on partial ground plane respectively. The proposed antenna is simulated on the FR4 substrate with a compact area of $30 \times 40 \times 0.8 \mathrm{~mm}^{3}$. The modification of the arm-length of U-shaped slot on the radiating patch and the variation of the 
dimension of the added notch on the partial ground plane, lead to an improvement in impedance widthband and in gain of the antenna structure. The topology of the proposed antenna is compact and is easy to design. Good VSWR and radiation pattern characteristics are obtained in the frequency band of interest. Simulation results depict that the proposed antenna could be a good candidate for WLAN, LTE and WiMAX applications.

\section{References}

[1] Balanis CA. Antenna Theory. John Wiley \& Sonc. Inc. 1997.

[2] Drabowitch S, Papiernik A. Smith. "Modern Antennas". Springer. 2005.

[3] Shi XF, Wang ZH, Su H, Zhao Y. A H-Type Microstrip Slot Antenna in Ku-band Using LTCC Technology with Multiple Layer Substrates. Second International Conference on Mechanic Automation and Control Engineering (MACE), Hohhot. 2011: 7104-7106.

[4] Boutejdar A, Ibrahim AA, Burte EP. A Compact Multiple Band-Notched Planer Antenna with Enhanced Bandwidth Using Parasitic Strip Lumped Capacitors and DGS-Technique. Indonesian Journal of Electrical Engineering and Computer Science. 2015; 13(2).

[5] Tendolkar P, Shah A, Jeyakumar A. Study of CPW-Fed Slot Antenna for UWB Application. International Journal of Innovative Research in Computer and Communication Engineering. 2015; 3(4).

[6] Zhou X, Quan X, Li R. A Dual-Broadband MIMO Antenna System for GSM/UMTS/LTE and WLAN Handsets. Antennas and Wireless Propagation Letters, IEEE. 2012; 11.

[7] Song Y, Jiao YC, Zhao G, Zhang FS. Multiband CPW-FED Triangle-Shaped Monopole Antenna for Wireless Applications. Progress in Electromagnetics Research, PIER. 2007; 70: 329-336.

[8] Parkash D. Design and Development of Cpw-Fed Mi-Crostrip Antenna for Wlan/Wimax Applications. Progress in Electromagnetics Research C. 2010; 17: 17-27.

[9] Gautam AK, Yadav S, Kanaujia BKA CPW-Fed Compact UWB Microstrip Antenna. IEEE ANTENNAS AND WIRELESS PROPAGATION LETTERS. 2013; 12.

[10] Kumar P, Tripathy MR, Sinha HP. Wide Band CPW Fed Slotted Microstrip Antenna. Indonesian Journal of Electrical Engineering and Computer Science. 2015; 15(1).

[11] Ibrahim AA, Abdalla MA, Boutejdar A. Hybrid Technique for Dual-Band Notched UWB Monopole Antenna. Microwaves \& RF magazine. 2016; 5 (6): 12-19.

[12] Kelly JR, Hall PS, Gardner P. Band-Notched UWB Antenna Incorporating a Microstrip Open-Loop Resonator. IEEE TRANSACTIONS ON ANTENNAS AND PROPAGATION. 2011; 59(8).

[13] Malik J, Kartikeyan MV. Stacked equilateral triangular patch antenna with Sierpinski gasket fractal for WLAN applications. Progress In Electromagnetics Research Letters. 2011; 22: 71-81.

[14] Malik J, Kartikeyan MV. Metamaterial inspired patch antenna with L-shape slot loaded ground plane for dual band (WiMAX/WLAN) applications. Progress in Electromag-netics Research Letters. 2012; 31: 35-43.

[15] Hu W, Yin YZ, Yang X, Fei P. Compact multiresonator-loaded planar antenna formultiband operation. IEEE Trans. Antennas Propag. 2013; 61(5): 2838-2841.

[16] Ahmed S, Farooq A. Shamim TA, Cheema HH. A Compact Kapton-based Inkjet Printed Multiband Antenna for Flexible Wireless Devices. IEEE Antennas and Wireless Propagation Letters. 2015.

[17] Huang S, Li J, Zhao JZ. A Novel Compact Planar Triple-Band Monopole Antenna for WLAN/WiMAX Applications. Progress In Electromagnetics Research Letters. 2014; 50: 117-123.

[18] Ahmed Al, Abdalla MA, Boutejdar A. A Printed Compact Band-Notched Antenna Using Octagonal Radiating Patch and Meander Slot Technique for UWB Applications. Progress In Electromagnetics Research M. 2017; 54: 153-162.

[19] Aneesh M, Siddiqui MG, Ansari JA., Singh A, Kamakshi K. Inset Feed Toppled H-Shaped Microstrip Patch Antenna for PCS/WiMAX Application. Indonesian Journal of Electrical Engineering and Computer Science. 2016; 1(2).

[20] Sürmeli K, Türetken B. "U-slot Stacked Patch Antenna Using High and Low Dielectric Constant Material Combinations in S-band". IEEE, 2011.

[21] Boutejdar A, Ahmed I, Burte E. Novel Microstrip Antenna Aims at UWB Applications. Microwaves \& RF magazine. 2015; 7(7): 8-14.

[22] Abdalla MA, Ibrahim AA, Boutejdar A. Resonator switching techniques for notched ultra-wideband antenna in wireless applications. IET Microwaves, Antennas \& Propagation. 2015; 9 (13): 1468-1477.

[23] Boutejdar AW, Abd Ellatif W. A novel compact UWB monopole antenna with enhanced bandwidth using triangular defected microstrip structure and stepped cut technique, Microwave and Optical Technology Letters. 2016; 58(6): 1514-1519.

[24] Chong CC, Watanabe F, Inamura H. Potential of UWB Technology for the next Generation Wireless Communications. IEEE Ninth International Symposium on Spread Spectrum Techniques and Application. 2006. 
[25] Weigand S, Huff GH, Pan KH, Bernhard JT. Analysis and Design of Broad-band Single Layer Rectangular U-slot Microstrip Patch Antennas. IEEE Trans. on Antennas and Propagation. 2003; $51(3)$.

[26] Bhalla R, Shafai L. Resonance Behavior of Single U-slot Microstrip Patch Antenna. Microwaveand Optical Technology Letters. 2002; 32(5): 333-335.

[27] Kumar S, Beniwal NS, Srivastava DK. Bandwidth Enhancement by slot loaded Patch Antenna for GPS/WLAN/WiMAX Applications. International Journal of Advanced Research in Computer and Communication Engineering. 2014; 3(1).

[28] AF Morabito, AR Lagana, T Isernia. "Isophoric array antennas with a low number of control points: a 'size tapered' solution". Progress In Electromagnetics Research Letters. 2013; 36: 121-131.

[29] Morabito AF, Laganà AR, Sorbello G, Isernia T. Mask-constrained power synthesis of maximally sparse linear arrays througha compressive-sensing-driven strategy. Journal of Electromagnetic Waves and Applications. 2015; 29(10): 1384-1396.

[30] Ansari JA, Ram RB. Broadband Stacked U-slot Microstrip Patch Antenna. Progress In Electromagnetics Research Letters. 2008; 4: 17-24.

[31] Mishra S, Hadaand OS. Broadband Microstrip Patch Antenna using Slot. International Journal of Computer Application (0975-8887). 2014; 108(6).

[32] Boutejdar A, Amzi M, Bennani SD. Design and Improvement of a Compact Bandpass Filter using DGS Technique for WLAN and WiMAX Applications. TELKOMNIKA (Telecommunication, Computing, Electronics and Control). 2017; 15(3).

[33] AliY EM, Jasim KAS. Design of Broadband Microstrip Patch Antenna for WLAN/WiMAX Applications. Al-Rafidain Engineering. 2015; 23(1).

[34] Zimu Y, Hou Z, Leiming Z, An W. A U-shaped Slot Antenna for WLAN and WiMAX Applications. Progress in Electromagnetic Research Symposium. 2014: 25-28.

[35] Boutejdar A, Challal M, Bennani SD, F Mouhouche, K Djafri. Design and Fabricationof a Novel Quadruple-Band Monopole Antenna Using a U-DGS and Open-Loop-Ring Resonators. Advanced Electromagnetics. 2017; 6(3), 59-63.

[36] Morabito AF. Power Synthesis of Mask-Constrained Shaped Beams Through Maximally-Sparse Planar Arrays. Telkomnika (Telecommunication Computing Electronics and Control). 2016; 14(4): 1217-1219.

[37] Liu L, Cheung SW, Yuk TI. Bandwidth improvements using ground slots for compact UWB microstripfed antennas. Progress in Electromagnetics Research Symposium Proceedings (PIERS). 2011:1420-1423.

[38] Cruz JN et al. Parametric Study of Printed Monopole Antenna Bioinspired on the Inga Marginata Leaves for UWB Applications. Journal of Microwaves, Optoelectronics and Electromagnetic Applications. 2017; 16(1): 312-322. 